\title{
Biological characterization and analysis of metastasis-related genes in cell lines derived from the primary lesion and lymph node metastasis of a squamous cell carcinoma arising in the mandibular gingiva
}

\author{
TAKAHIRO FUJINAGA ${ }^{1 *}$, WATARU KUMAMARU ${ }^{1 *}$, TSUYOSHI SUGIURA $^{2}$, \\ YOSUKE KOBAYASHI $^{1}$, YUKIKO OHYAMA ${ }^{1}$, TATSUYA IKARI ${ }^{1}$, MITSUHO ONIMARU $^{3}$, \\ NAONARI AKIMOTO ${ }^{1}$, RUMI JOGO ${ }^{1}$ and YOSHIHIDE MORI ${ }^{1}$
}

Sections of ${ }^{1}$ Oral and Maxillofacial Surgery, ${ }^{2}$ Oral and Maxillofacial Oncology, Division of Maxillofacial Diagnostic and Surgical Sciences, Faculty of Dental Science, Kyushu University; ${ }^{3}$ Division of Pathophysiological and Experimental Pathology, Department of Pathology, Graduate School of Medical Sciences, Kyushu University, Higashi-ku, Fukuoka 812-8582, Japan

Received December 5, 2013; Accepted January 28, 2014

DOI: 10.3892/ijo.2014.2332

\begin{abstract}
Controlling metastatic lesions is an important part of improving cancer prognosis, in addition to controlling the primary lesion. There have been numerous histological studies on primary and metastatic lesions, but little basic research has been performed using cell lines from primary and metastatic lesions belonging to the same patient. In this study, we successfully established a cell line derived from lower gingival carcinoma (WK2) as well as a line derived from secondary cervical lymph node metastasis (WK3F) through primary cultures of tissue from a patient with oral squamous cell carcinoma. We then investigated the biological characteristics of the cancer cell lines from these primary and metastatic lesions and analyzed metastasis-related genes. Comparison of the biological characteristics in vitro showed that WK3F had higher cell proliferation ability and shorter cell doubling time than WK2. WK3F also had increased cell migratory ability and higher invasive and self-replication abilities. Heterotransplantation into nude mice resulted in high tumor formation rates in the tongue and high metastasis rates in the cervical lymph nodes. Changes in WK2 and WK3F gene expression were then comprehensively analyzed using microarrays. Genes with increased expression in WK3F compared
\end{abstract}

Correspondence to: Dr Wataru Kumamaru, Section of Oral and Maxillofacial Surgery, Division of Maxillofacial Diagnostic and Surgical Sciences, Faculty of Dental Science, Kyushu University, 3-1-1 Maidashi, Higashi-ku, Fukuoka 812-8582, Japan

E-mail:kumamaru@dent.kyushu-u.ac.jp

*Contributed equally

Key words: cancer cell line, biological characteristic, metastasisrelated gene, microarray to $\mathrm{WK} 2$ were extracted when the Z-score was $\geq 2.0$ and the ratio was $\geq 5.0$, while genes with reduced expression in $\mathrm{WK} 3 \mathrm{~F}$ compared to WK2 were extracted when the Z-score was $\leq-2.0$ and the ratio was $\leq 0.2$; differences were found in 604 genes. From these, MAGEC1 (88.0-fold), MMP-7 (18.6-fold), SNAI1 (6.6-fold), MACC1 (6.2-fold), and HTRA1 (0.012-fold) were selected as metastasis-related candidate genes. The results suggest that these molecules could be important for clarifying the mechanisms that regulate metastasis and provide new therapeutic targets for inhibiting tumor invasion.

\section{Introduction}

Cancers migrate from the regions in which they arise (primary lesion), enter and move through the blood vessels, and metastasize in regional lymph nodes or distal locations. Although cure rates have improved with cancers that are limited to the primary lesion, the prognosis of patients with metastasis remains poor. Thus, controlling metastatic lesions in addition to primary lesions is important for improving the prognosis of all cancers, not just oral cancers. The foundation for research on metastasis was laid by Fidler et al (1) in 1973 when they succeeded in deriving highly metastatic cells from mouse melanoma B16 cells that had a low ability to metastasize, and then using them to establish a metastasis experimental model. Since then, research on the mechanism of metastasis at the cellular and molecular levels has developed rapidly.

In the field of oral cancer, Hayashi et al (2) established the MO-T cell line derived from a tongue primary lesion and the MO-N1 and MO-N2 cell lines from cervical lymph node metastasis. Reports such as those by Easty et al (3) on the HN-6 cell line derived from a tongue primary lesion and the HN-6n1 and HN-6n2 cell lines from cervical lymph node metastasis, in addition to that by Nobumori et al (4) on KK-p from a tongue primary lesion and KK-m from cervical lymph node metastasis, have indicated that the biological characteristics of 
primary lesions differ from those of metastatic lesions. Since there are still only a few cell lines from primary and metastatic lesions with different biological characteristics, establishing and comparing such cell lines would be useful in elucidating the mechanism underlying metastasis.

Herein, we established a cell line from a lower gingival carcinoma primary lesion (WK2) and a line from a secondary cervical lymph node metastasis (WK3F) from the same patient. The biological characteristics of the lines were compared and analysis of metastasis-related genes was conducted.

\section{Materials and methods}

Primary culture. WK2 was established from a lower gingival carcinoma from a 58-year-old male patient who had not undergone preoperative therapy (5). WK3 was established from secondary cervical lymph node metastases of the lower gingival carcinoma from the same patient 7 months later. However, WK3 did not have stable growth. In this study, WK3F was established from WK3 by repeatedly selecting colonies that grew stably. This study design was approved by the appropriate ethics review boards of Kyushu University. This patient provided written, informed consent.

Cell culture. WK2 and WK3F, which was established from WK3, were used for various experiments. In addition, we used the human tongue oral squamous cell carcinoma cell lines HSC3 and SAS and human lung fibroblast cell line VA13 which WI38 was transformed by SV40 virus.

These cell lines were maintained in Dulbecco's modified Eagle's medium (DMEM; Sigma-Aldrich, St. Louis, MO, USA) supplemented with $10 \%$ fetal bovine serum (FBS; Filton Pty, Brooklyn, Australia), 2 mM l-glutamine (Wako Pure Chemical Industries, Osaka, Japan), penicillin G (Meiji Seika Pharma, Tokyo, Japan), and streptomycin (Meiji Seika Pharma) in a $5 \% \mathrm{CO}_{2}$ incubator at $37^{\circ} \mathrm{C}$. The cell lines were passaged using $0.05 \%$ trypsin/EDTA (Gibco, Grand Island, NY, USA) and phosphate-buffered saline (PBS).

Plasmid and transfection. WK2, HSC3, SAS, VA13 cells were transfected with the pAcGFP-N1 vector (Clontech, Palo Alto, CA, USA), while WK3F cells were transfected with the pDsRed-Express2-N1 vector (Clontech) using Lipofectamine LTX (Invitrogen, Carlsbad, CA, USA) according to the manufacturer's instructions. Colonies that exhibited resistance to geneticin (G418; Sigma-Aldrich) were pooled from the individual transfection experiments. In order to obtain cells that homogeneously expressed green fluorescent protein (GFP) and red fluorescent protein (RFP), a pool of geneticin resistant colonies was selected using green and red fluorescence. All selected cells were maintained in DMEM containing $10 \%$ fetal bovine serum and $1 \mu \mathrm{g} / \mathrm{ml}$ geneticin.

MTT assay. Each cell line was seeded onto a 96-well plate at a density of $5 \times 10^{3}$ cells per well and incubated in DMEM containing $10 \%$ FBS for $8 \mathrm{~h}$. After incubation, each cell line was analyzed by CellTiter 96 Aqueous Non-radioactive Cell Proliferation Assay G4000 (Promega, Madison, WI, USA) according to the manufacturer's instructions. The absorbance of samples at $590 \mathrm{~nm}$ was measured with a microplate reader (model 680; Bio-Rad Laboratories, Hercules, CA, USA) with the results from the first day used as the baseline (absorbance $=1$ ). Analysis of cell proliferation was performed on each day for 14 days. All experiments were carried out in triplicate and repeated 3 times.

Cell doubling time was calculated by utilizing the known mathematical formula for tumor doubling (6).

$$
\text { Doubling time }=T_{i} \times\left[\log 2 / 3 \times \log \left(D_{i} / D_{o}\right)\right]
$$

where $T_{i}$ is the interval time, $D_{i}$ is the absorbance from the second day, and $\mathrm{D}_{\mathrm{o}}$ is the absorbance from the third day.

Wound healing assay. Each cell line $\left(3 \times 10^{5}\right)$ was seeded on a 6-well plate, and $24 \mathrm{~h}$ later 'wounds' were scratched with a 200- $\mu 1$ pipette tip, washed with medium, and observed under a fluorescence microscope (BZ-8000; Keyence, Osaka, Japan). The wound regions were photographed again after 3, 6, 9, $12,15,18,21$ and $24 \mathrm{~h}$, in order to measure the wound area. Wound area was standardized by using the following formula: Wound area $(\%$ of control $)=$ Wound area after the indicated period x100/initial wound area. All experiments were carried out in triplicate and repeated 3 times.

Evaluation of tumor dissemination from the primary cancer nest. Evaluation of tumor dissemination from the primary cancer nest was modified from the procedure developed by Abe et al (7). In brief, $1 \times 10^{6}$ cells from each fluorescently labeled cell line were mixed in $10 \mu \mathrm{l}$ collagen type I gel to form a solid cell cluster. The collagen-embedded cell lines were allowed to solidify for $30 \mathrm{~min}$ at $37^{\circ} \mathrm{C}$ in a $100-\mu 1$ microcentrifuge tube. The collagen-embedded cell lines were embedded in collagen type I gel $\left(1 \times 10^{5}\right.$ cells $\left./ \mathrm{ml}\right)$ containing fibroblasts and solidified. The fibroblast was derived from the WK2 and WK3F patient. Growth medium was placed over the collagen gels and cultured. Tumor dissemination was observed under a fluorescence microscope (BZ-8000; Keyence). The grade of tumor dissemination from the tumor cell pellet was evaluated by measuring the moving distance of farthest cells from the edge of the nest in each of the regions. The divided region is 12 regions by 5 degrees from the center of the aggregate. The evaluation was done after 7 days. All experiments were carried out in triplicate and repeated 3 times.

Sphere-forming assay. Evaluation of self-replication was performed as previously described (8). WK2 and WK3F were seeded at a density of $5 \times 10^{4}$ cells $/ \mathrm{ml}$ in $60-\mathrm{mm}$ noncoated dishes with serum-free DMEM containing $40 \mathrm{ng} / \mathrm{ml}$ basic fibroblast growth factor (bFGF; Invitrogen) and $20 \mathrm{ng} / \mathrm{ml}$ epidermal growth factor (EGF; Invitrogen) for floating cultures. The cells were cultured in a humidified incubator in an atmosphere of $5 \% \mathrm{CO}_{2}$ at $37^{\circ} \mathrm{C}$, in the presence of bFGF and EGF, which were added to the medium every other day. After 10 days, the diameters of the cell clusters that had developed were measured, and cell clusters with a diameter $>100 \mu \mathrm{m}$ were counted as spheres. For passaging, primary spheres (day 10) were treated with $0.05 \%$ trypsin/EDTA and dissociated into single cells, after which the cells were added to 24 -well culture plates at a density of $1 \times 10^{4}$ cells $/ \mathrm{ml}$ in serum-free medium. The cells were cultured for a further 10 days in serum-free medium to 
obtain secondary spheres. In the same way, the diameters of the developed cell clusters were measured, and cell clusters with a diameter $>100 \mu \mathrm{m}$ were counted as spheres.

Heterotransplantation of WK2-GFP and WK3F-RFP into nude mice. All animal experimental protocols used in this study were approved by the Animal Care and Use Committee of Kyushu University. Experiments were conducted using 8-week-old female athymic nude mice (BALB/cA Jcl-nu/nu) purchased from Kyudo (Fukuoka, Japan). The mice were housed in laminar flow cabinets under specific pathogen-free conditions in facilities approved by Kyushu University. For the experimental metastasis studies, $1 \times 10^{6}$ cells in $40 \mu 1$ PBS were injected into the tongue using a syringe with a 27 -gauge disposable needle (TOP Plastic Syringe, Tokyo, Japan) under inhalation anesthesia using sevoflurane. The primary tumor volumes were measured weekly, and mice were sacrificed when the primary tumor volume reached $100 \mathrm{~mm}^{3}$ or when 60 days had passed after the injection. After sacrifice, tumors of the tongue and metastases from tongue tumors in the cervical lymph nodes were visualized macroscopically under light excitation.

Total RNA isolation. Total RNA was isolated from WK2 and WK3F using TRIzol Reagent (Invitrogen) and was purified using an SV Total RNA Isolation System (Promega) according to the manufacturer's instructions. RNA samples were quantified with an ND-1000 spectrophotometer (NanoDrop Technologies, Wilmington, DE, USA), and the quality was confirmed with an Experion System (Bio-Rad Laboratories).

Gene expression microarrays. The cRNA was amplified, labeled, and hybridized to a 60K Agilent 60-mer oligomicroarray (SurePrint G3 Human Gene Expression Microarray $8 \times 60$ K, v2; Agilent Technologies, Santa Clara, CA, USA) according to the manufacturer's instructions. All hybridized microarray slides were scanned by an Agilent scanner. Relative hybridization intensities and background hybridization values were calculated using the Agilent Feature Extraction software (9.5.1.1).

Data analysis and filter criteria. Raw signal intensities and flags for each probe were calculated from hybridization intensities (gProcessedSignal), and spot information (e.g., gIsSaturated), according to the procedures recommended by Agilent. Flag criteria for the GeneSpring Software: Absent (A): 'Feature is not positive and significant' and 'Feature is not above background'. Marginal (M): 'Feature is not uniform', 'Feature is saturated', and 'Feature is a population outlier'. Present (P): others. The raw signal intensities of two samples were $\log _{2}$-transformed and normalized by quantile algorithm with the 'preprocessCore' library package (9) by using the Bioconductor software (10).

We selected probes that called the 'P' flag in both samples. To identify up- and downregulated genes, we calculated Z-scores (11) and ratios (non-log scaled fold-change) from the normalized signal intensities of each probe for comparison between control and experiment sample. Then, we established criteria for regulated genes: upregulated genes, Z-score $\geq 2.0$ and ratio $\geq 5$-fold, downregulated genes, Z-score $\leq-2.0$ and ratio $\leq 0.2$. The extracted data were analyzed using DAVID (12) that is a database provided by National Institute of Allergy and Infectious Diseases (NIAID). Moreover, microarray date analysis was supported by Cell Innovator.

Statistical analysis. All data are shown as mean $\pm \mathrm{SD}$, analyzed via analysis of variance and Student's t-test, and processed by the statistical software SPSS 13.0. Statistical significance was assumed at $\mathrm{P}<0.05$.

\section{Results}

Primary culture. WK2, which was derived from a lower gingival carcinoma and WK3, which was established from a secondary cervical lymph node metastases from the same patient, were established in our laboratory. In this study, WK3F was established from WK3 by repeatedly selecting colonies that grew stably because WK3 was not able to grow stably.

Morphological characteristics of WK2 and WK3F and pathological findings for the original tumor. In the images obtained using phase-contrast microscopy, WK2 and WK3F cells were found to be arranged in a cobblestone pattern (Fig. 1A and $\mathrm{B})$. In addition, a few of the WK3F cells had an elongated fibroblast-like structure (Fig. 1B).

Histopathological findings from our examination of the primary tumor (Fig. 1C) indicated that the border of the tumor was unclear and that the large and small cancer nests were scattered. Moreover, the primary tumor had the shape of a well-differentiated carcinoma with a cancer pearl. On the other hand, images of the cervical lymph node metastases indicated that it had undergone funicular shaped proliferation (Fig. 1D).

Evaluation of proliferation ability. MTT assays were then used to evaluated the proliferation ability of each cell line. The proliferation ability of WK3F cells was found to be about 1.2 times higher than that of WK2 cells at 7 days, at which point the WK3F cells had reached confluence (Fig. 2). We also calculated the doubling time during the logarithmic growth phase. The doubling time for WK2 was $32 \mathrm{~h}$, whereas the doubling time for WK3F was $24 \mathrm{~h}$. WK3F doubled as compared to WK2 in two-thirds the time (Table I).

Evaluation of migratory ability. Migratory ability was examined by using a wound healing assay (Fig. 3). The wound area in WK2 cell cultures was $\sim 50 \%$ after $24 \mathrm{~h}$ as compared to $0 \mathrm{~h}$. On the other hand, the wound area of the WK3F cell cultures was $\sim 40 \%$ after $24 \mathrm{~h}$ (Fig. 3K). The migratory ability of WK3F was almost the same as that of the SAS and HSC3. These results demonstrate that $\mathrm{WK} 3 \mathrm{~F}$ had increased migratory ability when compared to WK2 $(\mathrm{P}<0.05)$.

Evaluation of invasive ability. As mentioned in Materials and methods, the evaluation of cancer cell invasion ability of the primary tumor was examined by a procedure that was developed by Abe et al (7). In this assay, invasion of such cell line is visualized as small green and red fluorescent spots escaping from the cell pellet, which mimics the primary cancer nest. Each cancer cell invasion was evaluated by using the distance 

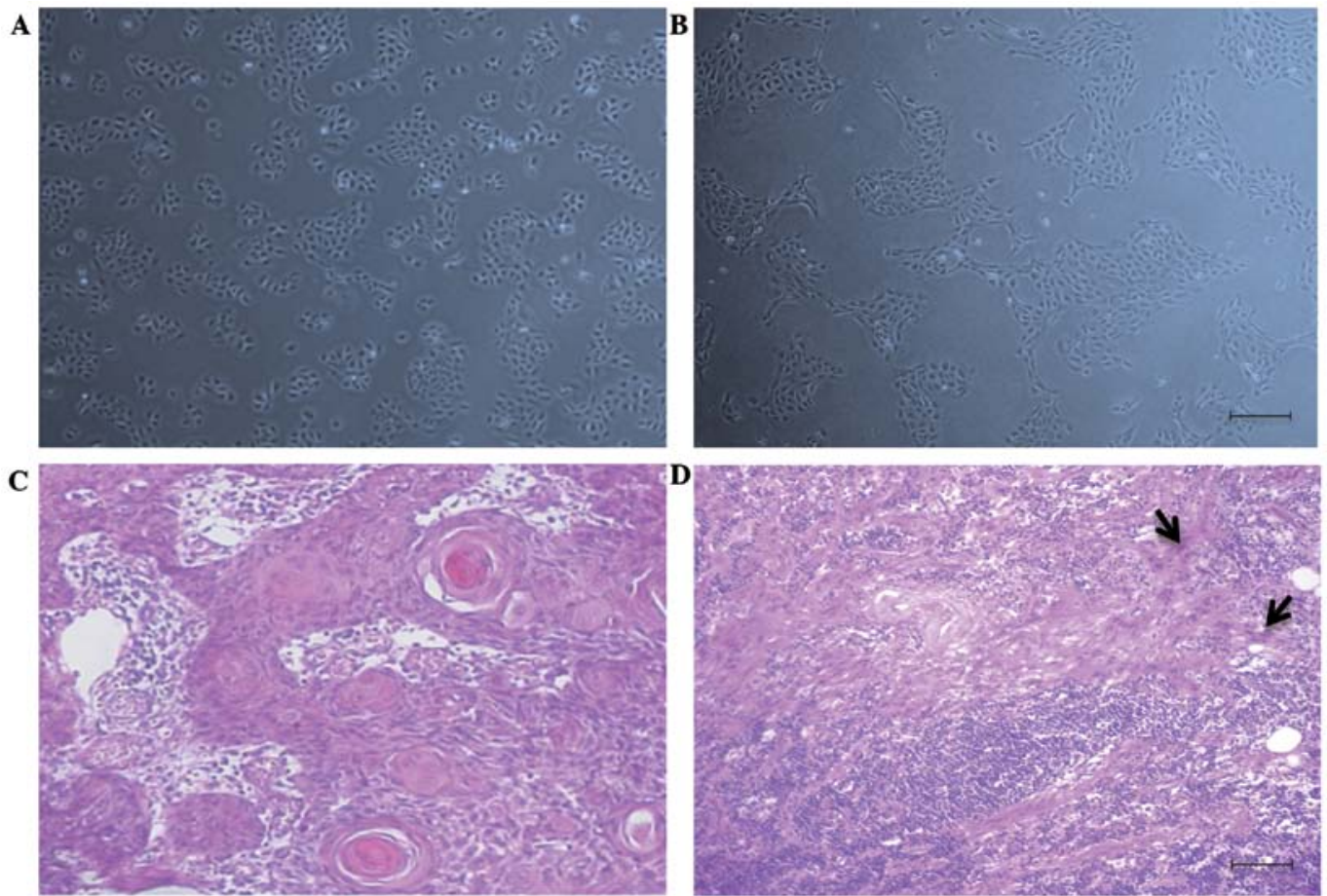

Figure 1. Microscope image of established cell lines and the original tumor. Phase difference microscope image of the established cell line WK2 (A) and WK3F (B). WK2 is derived from a mandibular gingiva carcinoma. WK3F is derived from subsequent cervical lymph node metastasis from the same patient. (C) The border of the primary tumor was unclear and the large and small cancer nests were scattered. Hematoxylin and eosin-stained histologic sections from the primary tumor and the lymph node metastasis (D). Cancer cell in metastatic lesion are labeled with arrowheads. (Bar, $100 \mu \mathrm{m}$ ).

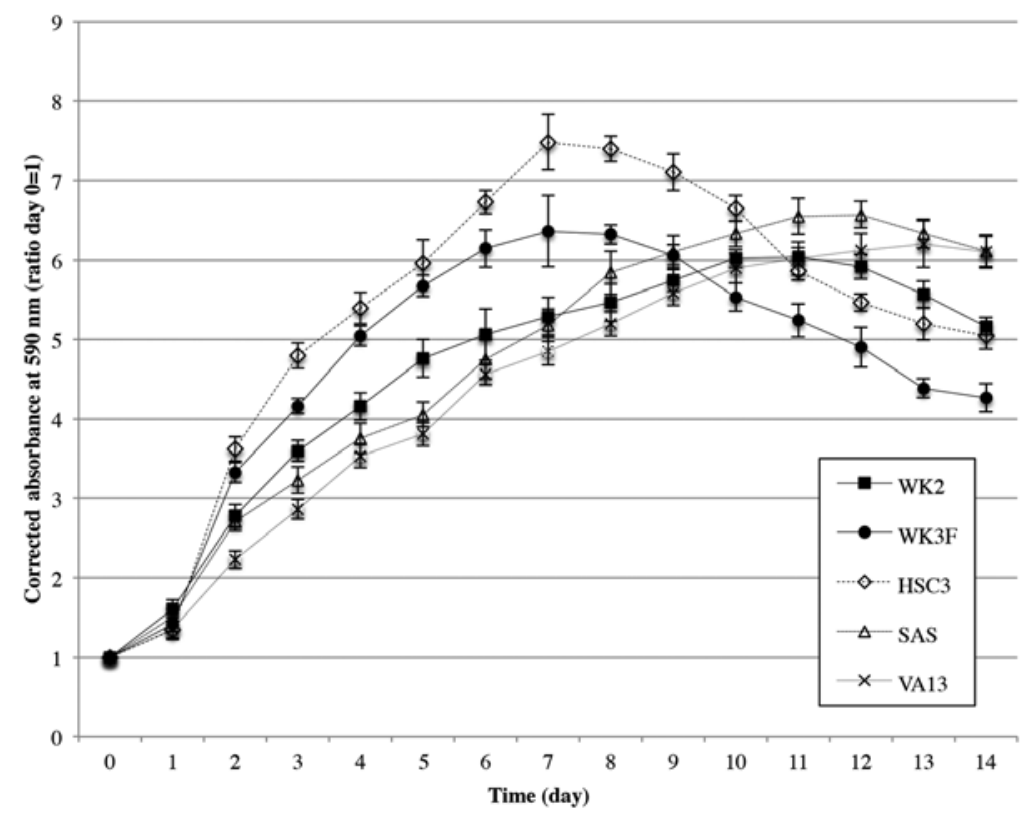

Figure 2. Cell growth curves for various cell lines. Cell growth was evaluated with the MTT assay. It was measured as the corrected absorbance at $590 \mathrm{~nm}$, standardized by using the absorbance at $590 \mathrm{~nm}$ on day 0 . Assays were performed in triplicate and repeated three times. The values were averaged and are indicated as the mean. Bars indicate the standard deviation.

Table I. Doubling time of various cell lines.

\begin{tabular}{lccccc}
\hline Cell lines & WK2 & WK3F & HSC3 & SAS & VA13 \\
\hline Doubling time (h) & 32 & 24 & 20 & 33 & 41 \\
\hline
\end{tabular}

Doubling time of WK2 was $32 \mathrm{~h}$, whereas doubling time of WK3F was $24 \mathrm{~h}$. The number of WK3F cells doubled in two-thirds the time it took WK2 cells to double. of the most invasive cells from the artificial primary cancer nest in each region shown in Fig. 4F.

As shown in Fig. 4A, invasive cells were hardly observed in WK2-GFP. In contrast, WK3F-RFP cells demonstrated aggressive cell invasion into artificial stromal tissue (Fig. 4B). Fig. 4G shows a comparison of the invasiveness of each cell line. The distance of the invasive cells was higher by about two-fold in WK3F-RFP as compared to WK2-GFP (P<0.001). 

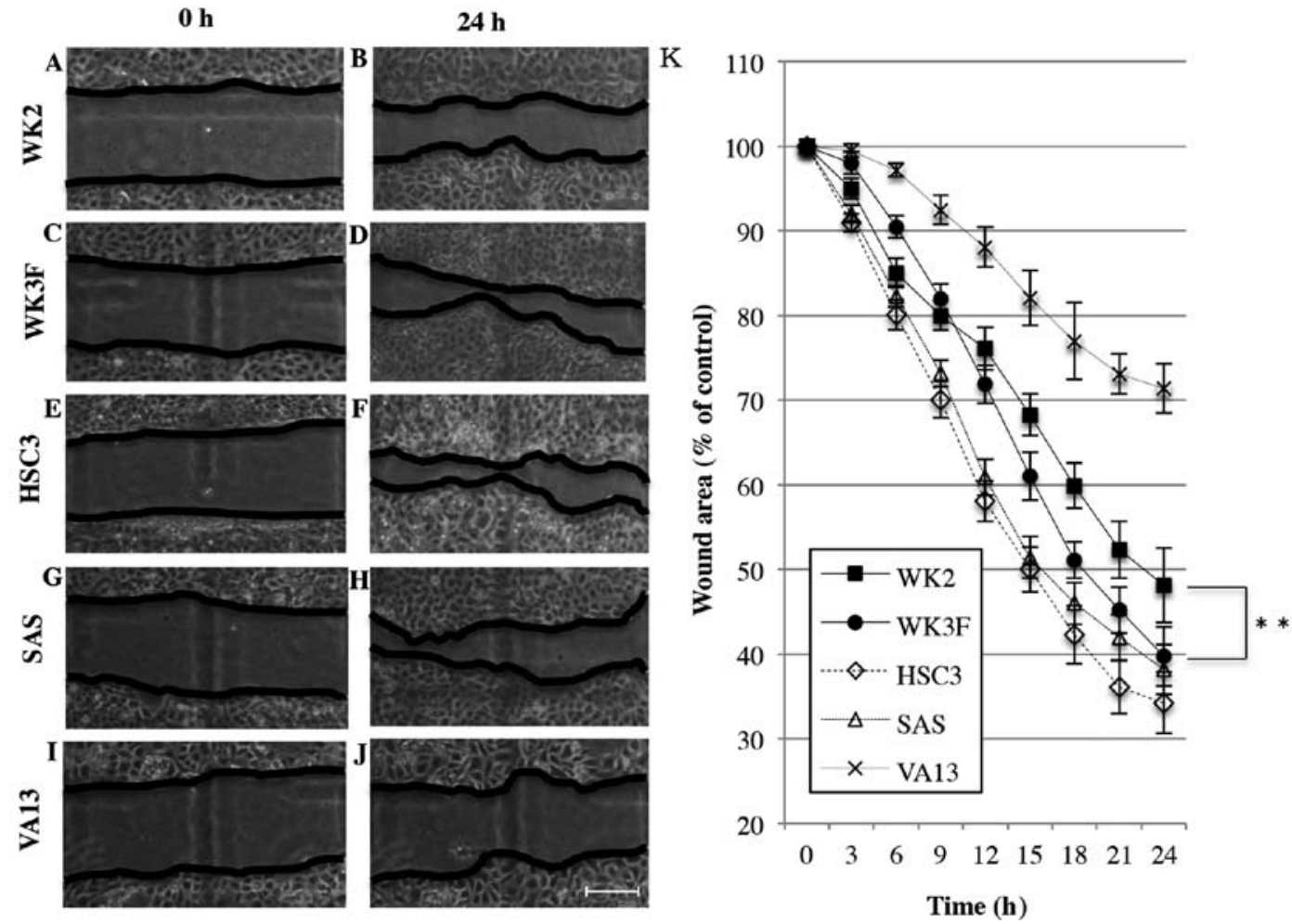

Figure 3. Cell migration of each cell line. Cell migration was evaluated by using a wound healing assay as described in Materials and methods. The wound regions were photographed $24 \mathrm{~h}$ after the start of the assay ( $0 \mathrm{~h}, \mathrm{~A}, \mathrm{C}, \mathrm{E}, \mathrm{G}, \mathrm{I} ; 24 \mathrm{~h}, \mathrm{~B}, \mathrm{D}, \mathrm{F}, \mathrm{H}, \mathrm{I})$. (A) WK2, (C) WK3F, (E) HSC3, (G) SAS, and (I) VA13 cells. (K) Wound area was standardized by the following formula: Wound area (\% of control) $=$ wound area after the indicated period x100/initial wound area. Bars indicate the standard deviation. Data significance was analyzed by Student's t-test. ${ }^{* *} \mathrm{P}<0.05$. Bar, $100 \mu \mathrm{m}$.
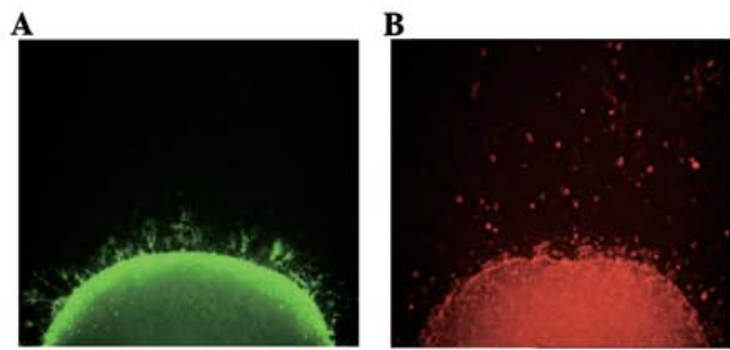

C

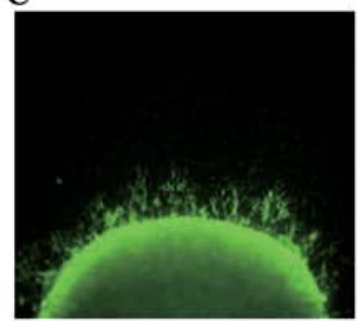

D

$\mathbf{E}$
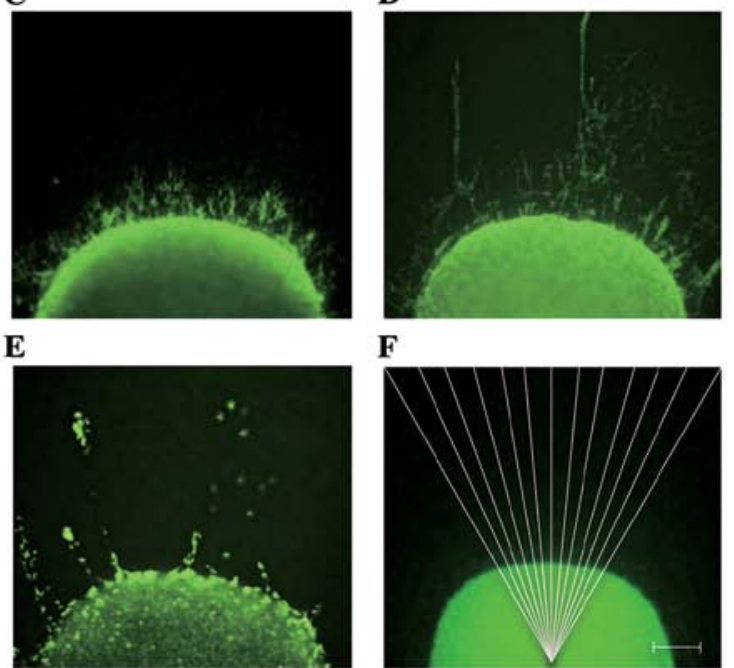

$\mathbf{F}$

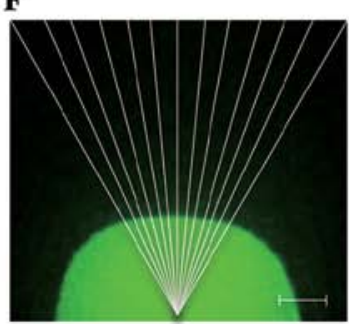

G

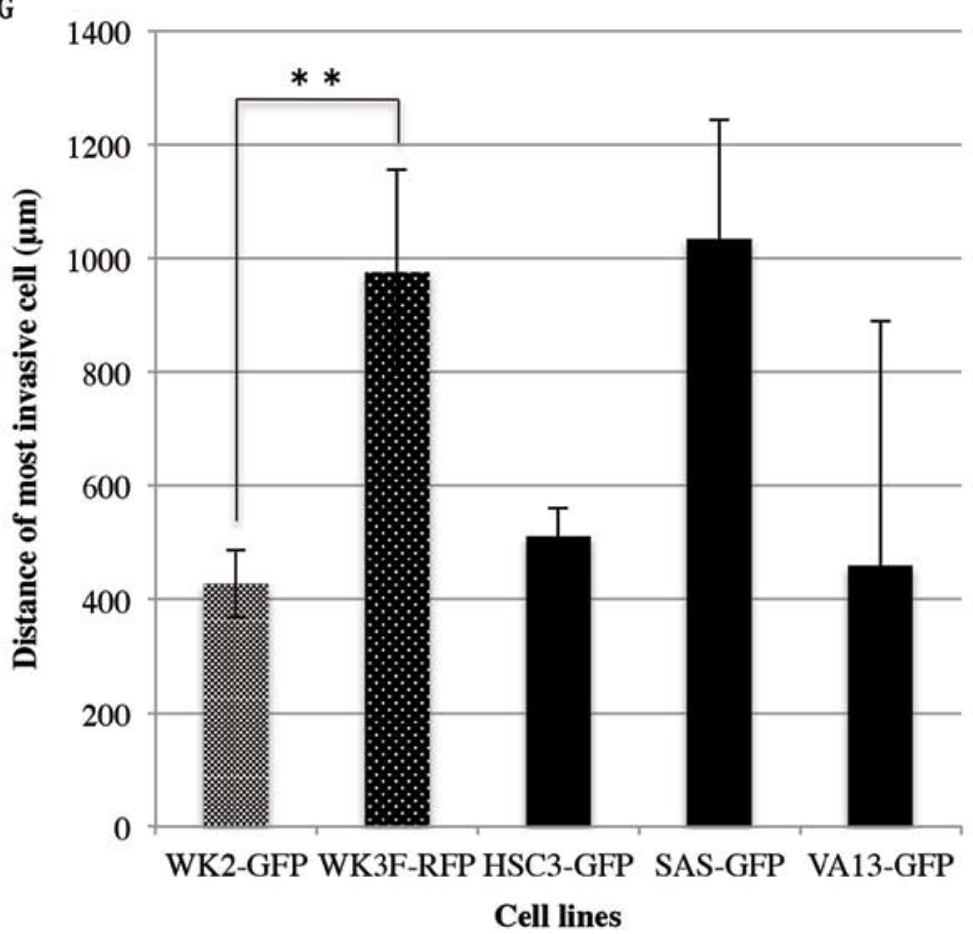

Figure 4. Invasive capacity of each cell line. WK2-GFP (A), WK3F-RFP (B), HSC3-GFP (C), SAS-GFP (D), and VA13-GFP (E) were analyzed with the invasion assay described in Materials and methods. (G) A comparison of the invasiveness of each cell line. The fluorescence of the cancer cells was visualized by excitation light, and photographs were taken after a 7-day incubation. Evaluation was carried out as described in Materials and methods. All experiments were performed at least three times, and representative results are shown. The values were averaged. Bars indicate the standard deviation. Data significance was analyzed by Student's t-test. ${ }^{* *} \mathrm{P}<0.05$. Bar, $500 \mu \mathrm{m}$. 
$\mathbf{A}$

A

$\mathbf{C}$

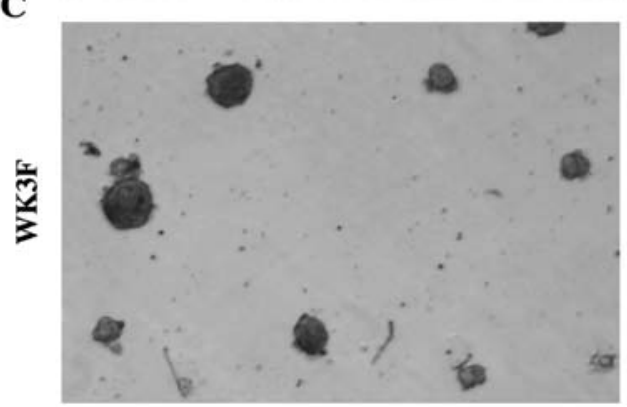

$\mathbf{E}$

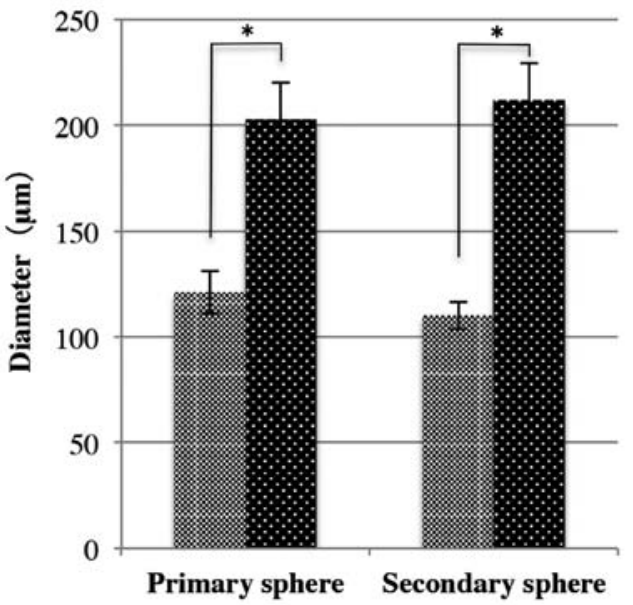

B

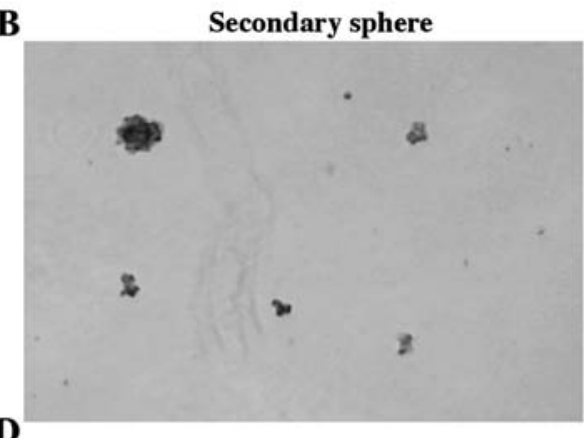

D

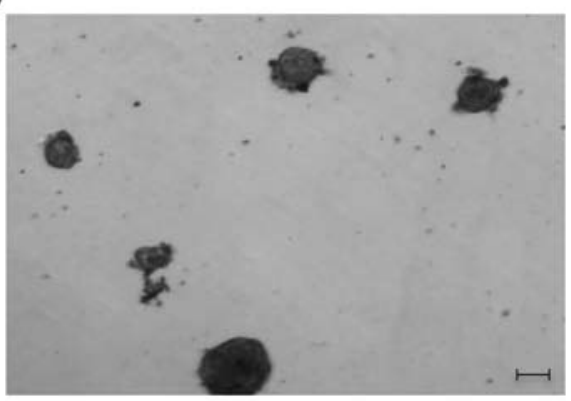

$\mathbf{F}$

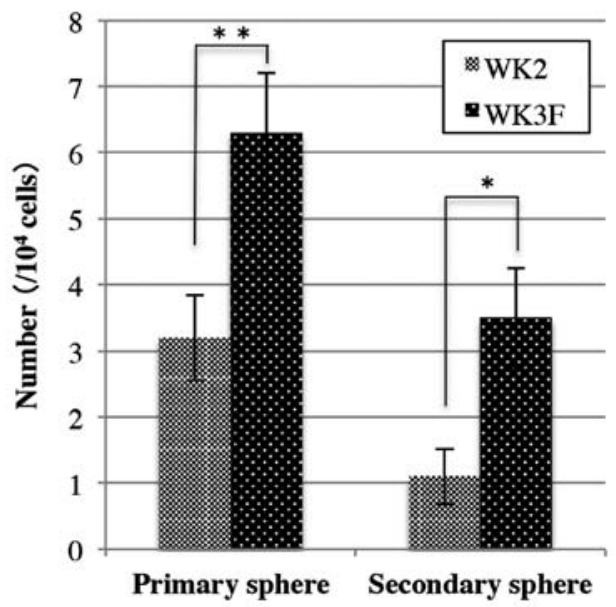

Figure 5. Sphere-forming ability of established cell lines. WK2 and WK3F cells were cultured at a density of $5 \times 10^{4}$ cells/ml in serum-free medium containing $40 \mathrm{ng} / \mathrm{ml} \mathrm{bFGF}$ and $20 \mathrm{ng} / \mathrm{ml}$ EGF for floating cultures for 10 days (primary spheres) (A and C). For secondary spheres, primary spheres (day 10) were dissociated into single cells and further cultured at a density of $1 \times 10^{4}$ cells $/ \mathrm{ml}$ for 10 days (B and D). Spheres were observed under a phase contrast microscope. Sphere diameters were measured (E), and spheres with a diameter $>100 \mu \mathrm{m}$ were counted. Sphere numbers were standardized as sphere number $/ 10^{4}$ cells originally cultured $(\mathrm{F})$ in each sphere period. Experiments were performed in triplicate, and the values were averaged. Bars indicate the standard deviation. Data significance was analyzed by Student's t-test. ${ }^{*} \mathrm{P}<0.001,{ }^{* *} \mathrm{P}<0.05$. Bar, $100 \mu \mathrm{m}$.

Table II. Tumorigenicity and metastasis of established cell lines.

\begin{tabular}{lcrc}
\hline & Tumorigenesis & & Metastasis \\
\cline { 2 - 2 } Cell lines & $\begin{array}{c}\text { Tumorigenic mice } \\
(\%)\end{array}$ & & $\begin{array}{c}\text { Mice with cervical lymph } \\
\text { node metastasis }(\%)\end{array}$ \\
\hline WK2-GFP & $3 / 10(30)$ & & $1 / 3(33.3)$ \\
WK3F-RFP & $5 / 10(50)$ & & $3 / 5(60)$ \\
\hline
\end{tabular}

Evaluation of self-replication.WK2 and WK3F were evaluated for their ability to self-replicate, a cancer stem cell characteristic, by using the sphere-forming assay. WK2 cells were found to have weak sphere-forming capacity, with respect to both diameter and number (Fig. 5A and B), whereas WK3F cells showed significant sphere-forming capacity (Fig. 5C and D). The sphere diameter of WK3F was approximately twice that of WK2 in the primary and secondary spheres (Fig. 5E). Furthermore, the number of spheres was more different in the secondary spheres than in the primary spheres. The number of spheres formed by WK3F was $\sim 3$ times higher than that of WK2 (Fig. 5F). These data suggest that WK3F contains many cells with self-replication ability.

Evaluation of tumorigenicity and metastatic ability using heterotransplantation. WK2-GFP and WK3F-RFP tumorigenesis and metastasis in vivo were examined. Fig. 6 shows a tumor that formed in the tongue (A and E), its GFP and RFP excitation (B and $\mathrm{F}$ ) and the submandibular lymph node metastasis (C and G) and its GFP and RFP excitation (B and F). 

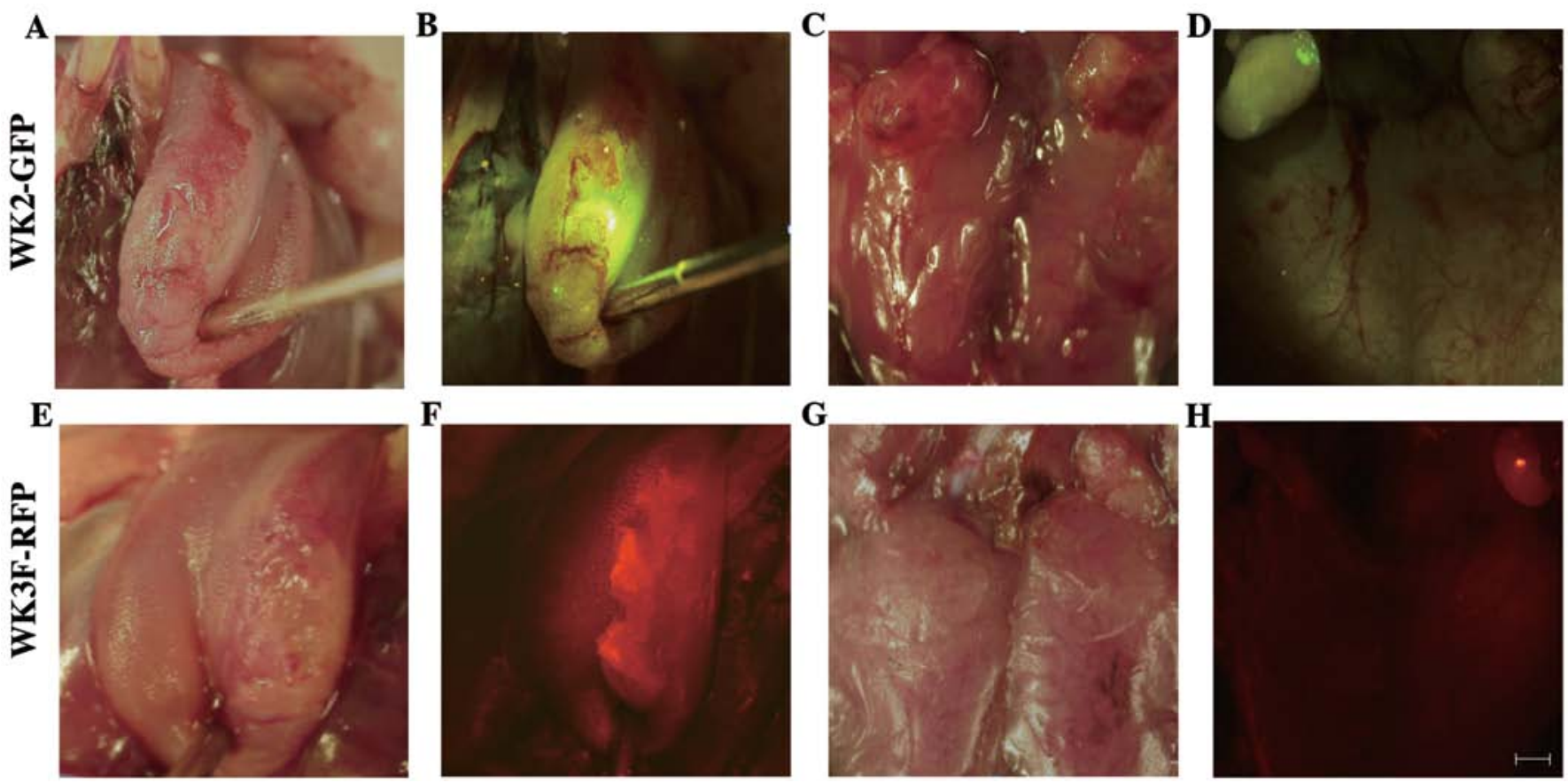

Figure 6. Evaluation of tumorigenicity and metastatic ability. WK2-GFP and WK3F-RFP were injected into the tongues of nude mice and examined to detect tumors in the tongue (A, B, E and F) and spontaneous metastases in submandibular lymph nodes (C, D, G and H). Observations with the naked eye (A, C, E and G) and the excitation of GFP (B and D) and RFP (F and H) are shown. The primary tumor volumes were measured weekly, calculated as the length $x$ width $x$ thickness, and mice were sacrificed when the primary tumor volume reached $100 \mathrm{~mm}^{3}$ or at 60 days after injection. Experiments were performed in 10 mice injected with each of the two established cell lines. Bar, $1000 \mu \mathrm{m}$.

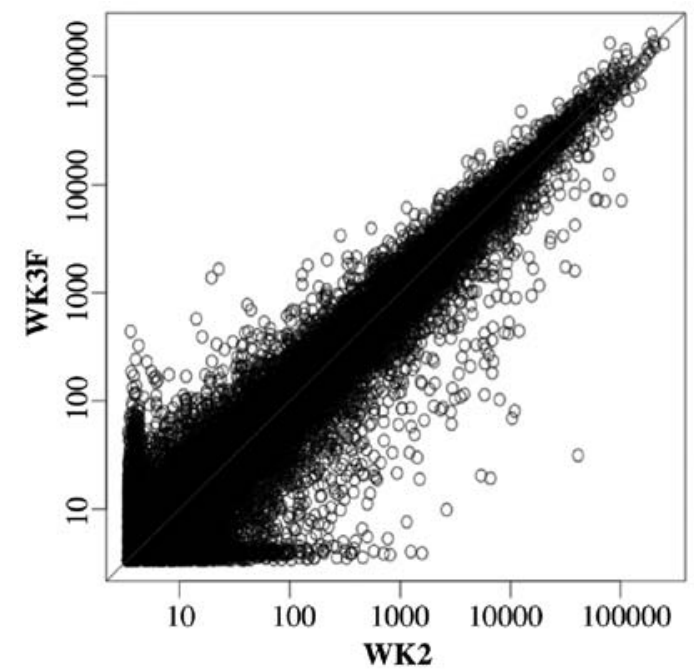

Figure 7. Scatter plot of the signal values of WK2 and WK3F. A scatter plot of the signal values of WK2 and WK3F gene expression shows data with high reliability.

Tumorigenesis (30\%) and metastasis (33.3\%) were observed in WK2-GFP. In contrast, tumorigenesis (50\%) and metastasis (60\%) were observed in WK3F-RFP (Table II). WK3F-RFP had higher tumorigenicity and metastatic ability than WK2-GFP.

Microarray analysis. Changes in WK2 and WK3F gene expression were comprehensively analyzed with the microarray method, using 50,599 gene probes to search for metastasisrelated genes. A scatter plot of the signal values of WK2 and WK3F gene expression shows data with little dispersion and high reliability (Fig. 7). Genetic differences were recognized when increased expression with a Z-score of $\geq 2.0$ and a ratio $\geq 5.0$ or reduced expression with a Z-score of $\leq-2.0$ and a ratio of $\leq 0.2$ were noted. Of these, we selected 15 upregulated and 15 downregulated candidate genes that are related to cancer or metastasis and whose functions are known (Fig. 8, Tables III and IV). Among these, the metastasis-related candidate genes with higher expression in WK3F than in WK2 were MAGEC1 (88.0-fold), which is a cancer antigen for malignant melanoma; matrix metallopeptidase 7 (MMP7) (18.6-fold), which is a matrix metalloproteinase; SNAI1 (6.6-fold), which is involved in the repression of E-cadherin transcription; and MACC1 (6.2-fold), which is related to the metastasis of colon cancer. High expression levels were observed in genes unrelated to metastasis, including EEF1A2 (60.1-fold) and BIRC3 (6.4-fold), which are related to anti-apoptosis; MAGEA11 (52.3-fold), which is a malignant melanoma antigen; and CLDN3 (9.3-fold) and PMP22 (6.3-fold), which are involved in cell adhesion.

Metastasis-related candidate genes with lower expression in WK3F than in WK2 were HTRA1 (0.012-fold), which regulates cell growth, and THBS2 (0.075-fold), which inhibits angiogenesis. Low expression levels were observed in genes unrelated to metastasis, such as CLCA2 (0.023-fold), which is related to cell adhesion.

\section{Discussion}

A positive correlation between regional lymph node metastasis and distal metastasis has been reported in head and neck cancer (13). Controlling the primary lesion is of course important for improving therapeutic results in oral cancer, but controlling metastatic lesions is also important. To 


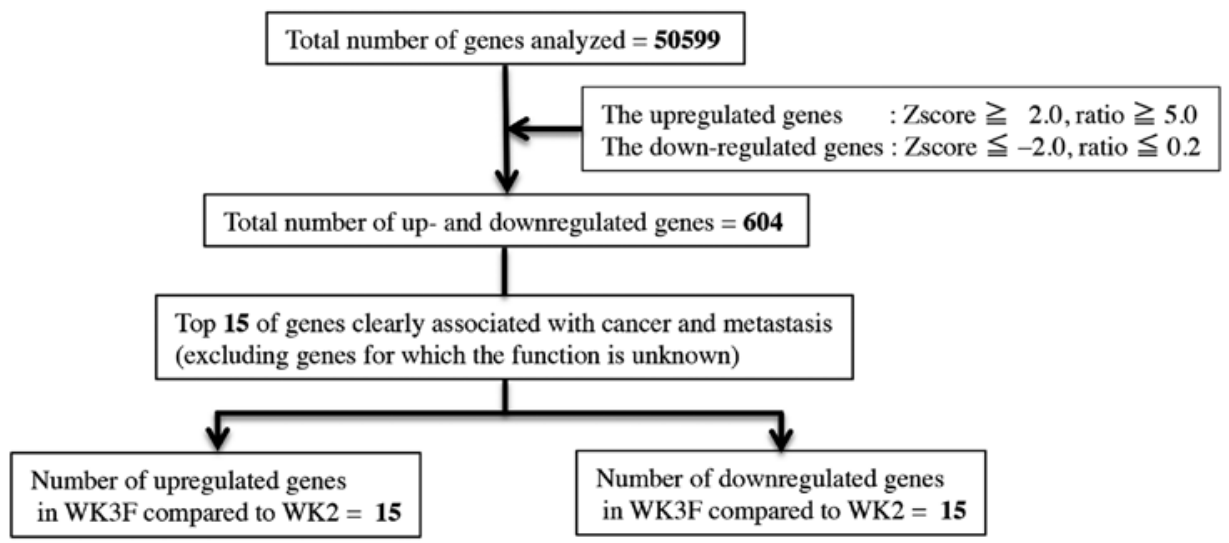

Figure 8. How to filter significant genes for cancer and metastasis. All 50599 genes were filtered by the process shown in this figure. Finally, 15 upregulated and 15 downregulated candidate genes that are related to cancer or metastasis and whose functions are known were selected.

Table III. The genes that were filtered (15 upregulated genes).

\begin{tabular}{|c|c|c|c|c|c|}
\hline ProbeID & $\begin{array}{l}\text { Gene } \\
\text { Symbol }\end{array}$ & Description & $\begin{array}{c}\mathrm{WK} 3 \mathrm{~F} / \mathrm{WK} 2 \\
\text { ratio }\end{array}$ & $\begin{array}{l}\text { Genbank } \\
\text { accession }\end{array}$ & Typical functions \\
\hline
\end{tabular}

A_23_P81898 UBD Ubiquitin D $147.13 \quad$ NM_006398 Protein binding,

A_23_P217178 MAGEC1 Melanoma antigen family C, 1

A_33_P3229953

EEF1A2 Eukaryotic translation elongation factor $1 \alpha 2$

A_23_P113553 MAGEA11 Melanoma antigen family A, 11, transcript variant 2

A_32_P219279

A_33_P3379001

A_33_P3248265

A_23_P52761

A_33_P3285565

A_24_P89891

A_33_P3397763

A_23_P131846

A_23_P98350

A_23_P100711

A_32_P131031
TRAF

BIRC3

Baculoviral IAP repeat containing 3, transcript variant 1

PMP22

Peripheral myelin protein 22, transcript variant 1

ELFN2 Extracellular leucine-rich repeat and fibronectin type III domain containing 2

UNC5A Unc-5 homolog A (C. elegans)

Lymphotoxin $\beta$ (TNF

superfamily, member 3 ), transcript variant 1

MMP7 Matrix metallopeptidase 7

(matrilysin, uterine)

CLDN3 Claudin 3

TNF receptor-associated factor 1 , transcript variant 1

TNFSF9 Tumor necrosis factor (ligand) superfamily, member 9

SNAI1 Snail homolog 1 (Drosophila)

MACC1 Metastasis associated in colon cancer 1
88.01 NM_005462 Protein binding

$60.15 \quad$ NM_001958 Nucleotide binding

52.34 NM_001011544 Protein binding

34.45 NM_052906 Negative regulation of phosphatase activity

$34.31 \quad$ NM_133369 Receptor activity

$28.21 \quad$ NM_002341 Receptor binding

18.57 NM_002423 Collagen catabolic process

9.3 NM_001306 Transmembrane receptor activity, tight junction

8.98 NM_005658 Protein binding, signal transduction

6.79 NM_003811 Receptor binding, cytokine activity

6.61 NM_005985 Negative regulation of transcription from RNA polymerase II promoter

6.4 NM_001165 Ubiquitin-protein ligase activity

6.35 NM_000304 Tight junction

6.24 NM_182762 Regulation of transcription 
Table IV. The genes that were filtered (15 downregulated genes).

\begin{tabular}{|c|c|c|c|}
\hline ProbeID & $\begin{array}{c}\text { Gene } \\
\text { Symbol }\end{array}$ & Description & $\begin{array}{c}\mathrm{WK} 3 \mathrm{~F} / \mathrm{WK} 2 \\
\text { ratio }\end{array}$ \\
\hline
\end{tabular}

$\begin{array}{ll}\text { A_24_P152398 TP53AIP1 } & \begin{array}{l}\text { Tumor protein p53 regulated } \\ \text { apoptosis inducing protein 1, } \\ \text { nuclear gene encoding } \\ \text { mitochondrial protein, } \\ \text { transcript variant } 2\end{array}\end{array}$

\begin{tabular}{|c|c|c|c|c|c|}
\hline A_33_P3227375 & THBS2 & Thrombospondin 2 & 0.075 & NM_003247 & $\begin{array}{l}\text { Structural molecule } \\
\text { activity }\end{array}$ \\
\hline A_23_P43810 & LTBP1 & $\begin{array}{l}\text { Latent transforming growth } \\
\text { factor } \beta \text { binding protein } 1 \text {, } \\
\text { transcript variant } 1\end{array}$ & 0.062 & NM_206943 & $\begin{array}{l}\text { Transforming growth } \\
\text { factor } \beta \text { receptor activity }\end{array}$ \\
\hline A_32_P44394 & AIM2 & Absent in melanoma 2 & 0.057 & NM_004833 & $\begin{array}{l}\text { Activation of innate } \\
\text { immune response }\end{array}$ \\
\hline A_23_P204947 & GJB2 & $\begin{array}{l}\text { Gap junction protein, } \beta 2 \text {, } \\
26 \mathrm{kDa}\end{array}$ & 0.05 & NM_004004 & Cell-cell signaling \\
\hline A_23_P203972 & FZD10 & Frizzled family receptor 10 & 0.034 & NM_007197 & Wnt-protein binding \\
\hline A_23_P397248 & CLCA2 & Chloride channel accessory 2 & 0.023 & NM_006536 & Chloride channel activity \\
\hline A_33_P3341499 & WNT5A & $\begin{array}{l}\text { Wingless-type MMTV } \\
\text { integration site family, } \\
\text { member } 5 \mathrm{~A}\end{array}$ & 0.018 & NM_003392 & $\begin{array}{l}\text { Activation of MAPK } \\
\text { activity, Wnt receptor } \\
\text { signaling pathway }\end{array}$ \\
\hline A_24_P935986 & BCAT1 & $\begin{array}{l}\text { Branched chain amino acid } \\
\text { transaminase } 1 \text {, cytosolic }\end{array}$ & 0.017 & NM_005504 & $\begin{array}{l}\text { G1/S transition of } \\
\text { mitotic cell cycle }\end{array}$ \\
\hline A_23_P354805 & KLF12 & Kruppel-like factor 12 & 0.016 & NM_007249 & $\begin{array}{l}\text { Negative regulation of } \\
\text { transcription from RNA } \\
\text { polymerase II promoter }\end{array}$ \\
\hline A_23_P97990 & HTRA1 & HtrA serine peptidase 1 & 0.012 & NM_002775 & Regulation of cell growth \\
\hline A_24_P55295 & GJA1 & $\begin{array}{l}\text { Gap junction protein, } \alpha 1 \text {, } \\
43 \mathrm{kDa}\end{array}$ & 0.009 & NM_000165 & Cell-cell signaling \\
\hline A_23_P119943 & IGFBP2 & $\begin{array}{l}\text { Insulin-like growth factor } \\
\text { binding protein } 2,36 \mathrm{kDa}\end{array}$ & 0.0046 & NM_000597 & $\begin{array}{l}\text { Regulation of cell } \\
\text { growth, protein binding }\end{array}$ \\
\hline A_33_P3379396 & KRT1 & Keratin 1 & 0.0026 & NM_006121 & $\begin{array}{l}\text { Complement activation, } \\
\text { structural constituent } \\
\text { of cytoskeleton }\end{array}$ \\
\hline A_21_P0011633 & KRT14 & Keratin 14 & 0.00066 & NM_000526 & $\begin{array}{l}\text { Structural constituent } \\
\text { of cytoskeleton }\end{array}$ \\
\hline
\end{tabular}

$0.1 \quad$ NM_001195195 Apoptosis


and metastatic lesion cell lines. WK3F, a cell line derived from secondary lymph node metastasis, did not exhibit formations of large cancer cell nests even in lymph node tissue images, and only microscopic metastases were observed. This, plus the fact that WK3F exhibited superior growth, migratory and metastatic abilities compared to the WK2 line, suggested that $\mathrm{WK} 3 \mathrm{~F}$ is a cell line that broke away from the primary lesion at an early stage. Comprehensive genetic analysis using microarrays was performed on the metastatic ability of these 2 cells to search for metastasis-related genes.

Metastasis-related candidate genes with higher expression in WK3F than WK2 were i) MAGEC1, which exhibits high expression levels in breast cancer, ovarian and non-small cell carcinoma, and metastatic malignant melanoma (14); ii) matrilysin (MMP7), which is correlated with invasive metastasis, recurrence, and poor prognosis in colon cancer (15); iii) SNAI1, which is involved in the repression of E-cadherin transcription (16), an adhesion molecule related to metastasis; and iv) MACC1, a modulator of the HGF-MET signal, which is important in predicting colon cancer metastasis (17). Overexpression of these genes has not been confirmed in metastatic lymph nodes from oral squamous cell carcinoma, and they deserve attention as new metastasis-related candidate genes for oral squamous cell carcinoma.

Ubiquitin D (UBD), which had the highest expression in WK3F compared to WK2, has been reported to correlate with the progression of colon cancer and is linked to recurrence in stage II-III cases after radical surgery (18). However, since ubiquitin is also reported to regulate biological responses in a variety of processes, including cellular mitosis, apoptosis, and the immune response, nothing conclusive can be said about this gene from the results of this study. The adhesion molecules CLDN3 and PMP22 exhibited higher expression in $\mathrm{WK} 3 \mathrm{~F}$ than in WK2, while CLCA2 was expressed at low levels. Chloride channel accessory 2 (CLCA2) is a target of the p53 family, which is reported to negatively regulate the migration and invasion of cancer cells (19). We thought that there was a connection among these proteins because growth and migration occurred while maintaining cell adhesion in the images obtained from the motion of WK3F.

Among the metastasis-related candidate genes with lower expression in WK3F than WK2, the disappearance of HTRA1 is reported to be involved in the metastatic ability of endometrial tumors (20). Further, HTRA1 serine protease has been reported to downregulate the progression of human melanomas and suppress the growth of metastatic melanoma cells (21). THBS2 belongs to the thrombospondin family and conducts cell-to-cell and cell-to-matrix interactions. This protein has been shown to function as an inhibitor of colon cancer metastasis and angiogenesis (22). High expression levels of this gene work to inhibit metastasis, but to determine if low expression levels promote metastasis, it needs to be shown that WK2 (which is a low metastatic line compared to WK3F) transforms into a high metastatic line in vivo by blocking individual WK2 gene functions. Keratin 1, which exhibited lower expression levels in $\mathrm{WK} 3 \mathrm{~F}$ than $\mathrm{WK} 2$, is a structural component of the cytoskeleton involved in keratinization, which is consistent with the more advanced keratinization observed in WK2 under confluent culture conditions. Keratin 14 is also a cytoskeleton structural component, and strongly positive images of this gene have been reported for cells on tumor extremities with high proliferative activity (23). We believe WK3F is a cancer cell line that detaches and metastasizes at an early stage from tumor extremities, which is not consistent with the aforementioned report.

EMT-induced cancer cells undergo changes in motility and other cell functions and are said to be involved in accelerating malignancy. Specifically, these cells acquire increased motility and invasive ability, drug tolerance, anoikis resistance, suppressed cellular aging, induced immunosuppression, and stem cell-like functions. The biological characteristics of WK3F indicated increased motility and invasive ability. Further, while E-cadherin is a representative adhesion molecule of epithelial cells, its expression is suppressed after EMT, which has made it a representative marker for EMT. The expression of SNAI1, a transcription factor that regulates E-cadherin expression, increased by 6.6 times in the microarray. Anoikis resistance was confirmed on analysis of self-replicating ability using sphere forming assays. Regarding the suppression of cellular aging, WK3, which was established from a metastatic lesion, could not grow beyond 25 passages. In other words, while the cancer cells possessed metastatic ability, cellular aging was still occurring. In contrast, WK3F continued for more than 150 passages. Since the expression of a gene (TP53AIP1) that regulates P53 was lower in WK3F than in WK2 in the microarray, it was surmised that this was acting to suppress cellular aging. The acquisition of stem cell-like functions (self-replicating ability, pluripotency) for WK3F was mainly evident in the microarray as a 34.4-fold increase in the expression of fibronectin (ELFN2), which is expressed by mesenchymal cells, and a 5.1-fold increase in prostate stem cell antigen (PSCA) expression. Induction of immunosuppression and drug tolerance are not confirmed. These facts suggest the existence of cells inside WK3F that can cause EMT, although this requires further investigation.

The early detachment of the metastatic cell line WK3F from the primary lesion naturally influences aspects such as cell adhesion molecules and matrix metalloproteinase, which are involved in invasion and migration, and factors that regulate cell growth. However, the fact that these cancer cells have acquired a variety of metastasis-related genes is also considered important. In the future, we would like to establish a high metastatic cell line from $\mathrm{WK} 3 \mathrm{~F}$, and by reinforcing or eliminating the expression of these metastasis-related candidate genes, confirm changes in the metastatic capacity of WK3F from changes in its biological characteristics and through heterotransplants into nude mice. By clarifying these aspects, we can elucidate the complex mechanism underlying metastasis and contribute to the development of therapeutic drugs.

\section{Acknowledgements}

This study was supported by Grants-in-Aid from the Ministry of Education, Culture, Sports, Science, and Technology of Japan (KAKEN no. 21792013 to W. Kumamaru, no. 25861958 to Y. Kobayashi and no. 23390465 to T. Sugiura).

\section{References}

1. Fidler IJ: Selection of successive tumour lines for metastasis. Nat New Biol 242: 148-149, 1973. 
2. Hayashi E, Hoteiya T, Nakanishi H, Momota Y, Nakano K, Fujisawa $\mathrm{K}$ and Nagayama M: Three oral cancer cell lines established from a patient and their characterization. Jap J Oral Maxillofacial Surg 43: 789-794, 1997 (In Japanese).

3. Easty SM, Easty GC, Carter RL, Monaghan P, Pittam MR and James T: Five human tumour cell lines derived from a primary squamous carcinoma of the tongue, two subsequent local recurrences and two nodal metastases. Br J Cancer 44 363-370, 1981

4. Nobumori T: Biological characteristics of two new cell strains isolated from a primary squamous cell carcinoma of the tongue and a nodal metastasis. J Hiroshima Univ Dental Soc 35: 18-32, 2003.

5. Kumamaru W, Nakamura S, Kadena T, Yamada A, Kawamura E, Sasaki M, Ohyama Y, Toyoshima T, Hayashida JN, Itoh K and Shirasuna K: T-cell receptor V $\beta$ gene usage by $\mathrm{T}$ cells reactive with the tumor-rejection antigen SART-1 in oral squamous cell carcinoma. Int J Cancer 108: 686-695, 2004.

6. Poullis M: Computed tomography surveillance scanning after lung cancer surgery: mathematical optimization of scanning interval based on tumour biology. Interact Cardiovasc Thorac Surg 17: 1-4, 2013

7. Abe M, Sugiura T, Takahashi M, Ishii K, Shimoda M and Shirasuna K: A novel function of CD82/KAI-1 on E-cadherinmediated homophilic cellular adhesion of cancer cells. Cancer Lett 266: 163-170, 2008.

8. Shimoda M, Sugiura T, Imajyo K, Ishii I, Chigita S, Seki K, Kobayashi Y and Shirasuna K: The T-box transcription factor Brachyury regulates epithelial-mesenchymal transition in association with cancer stem-like cells in adenoid cystic carcinoma cells. BMC Cancer 12: 377, 2012.

9. Bolstad BM, Irizarry RA, Astrand M and Speed TP: A comparison of normalization methods for high density oligonucleotide array data based on variance and bias. Bioinformatics 19: 185-193, 2003

10. Gentleman RC, Carey VJ, Bates DM, Bolstad B, Dettling M, Dudoit S, Ellis B, Gautier L, Ge Y, Gentry J, Hornik K, Hothorn T, Huber W, Iacus S, Irizarry R, Leisch F, Li C, Maechler M, Rossini AJ, Sawitzki G, Smith C, Smyth G, Tierney L, Yang JY and Zhang J: Bioconductor: open software development for computational biology and bioinformatics. Genome Biol 5: R80, 2004

11. Quackenbush J: Microarray data normalization and transformation. Nat Genet 32: 496-501, 2002.

12. Huang da W, Sherman BT and Lempicki RA: Systematic and integrative analysis of large gene lists using DAVID bioinformatics resources. Nat Protoc 4: 44-57, 2009.
13. Leemans CR, Tiwari R, Nauta JJ, van der Waal I and Snow GB: Regional lymph node involvement and its significance in the development of distant metastases in head and neck carcinoma. Cancer 71: 452-456, 1993

14. Jungbluth AA, Chen Y-T, Busam KJ, Coplan K, Kolb D, Iversen K, Williamson B, Van Landeghem FK, Stockert E and Lloyd J: CT7 (MAGE-C1) antigen expression in normal and neoplastic tissues. Int J Cancer 99: 839-845, 2002.

15. Adachi Y, Yamamoto H, Itoh F, Arimura Y, Nishi M, Endo T and Imai K: Clinicopathologic and prognostic significance of matrilysin expression at the invasive front in human colorectal cancers. Int J Cancer 95: 290-294, 2001.

16. Fernando RI, Litzinger M, Trono P, Hamilton DH, Schlom J and Palena C: The T-box transcription factor Brachyury promotes epithelial-mesenchymal transition in human tumor cells. J Clin Invest 120: 533-544, 2010.

17. Stein U, Walther W, Arlt F, Schwabe H, Smith J, Fichtner I, Birchmeier W and Schlag PM: MACC1, a newly identified key regulator of HGF-MET signaling, predicts colon cancer metastasis. Nat Med 15: 59-67, 2009.

18. Yan DW, Li DW, Yang YX, Xia J, Wang XL, Zhou CZ, Fan JW, Wen YG, Sun HC, Wang Q, Qiu GQ, Tang HM and Peng ZH: Ubiquitin $\mathrm{D}$ is correlated with colon cancer progression and predicts recurrence for stage II-III disease after curative surgery. Br J Cancer 103: 961-969, 2010.

19. Sasaki Y, Koyama R, Maruyama R, Hirano T, Tamura M, Sugisaka J, Suzuki H, Idogawa M, Shinomura Y and Tokino T: CLCA2, a target of the 553 family, negatively regulates cancer cell migration and invasion. Cancer Biol Ther 13: 1512-1521, 2012.

20. Mullany SA, Moslemi-Kebria M, Rattan R, Khurana A, Clayton A, Ota T, Mariani A, Podratz KC, Chien J and Shridhar V: Expression and functional significance of HtrA1 loss in endometrial cancer. Clin Cancer Res 17: 427-436, 2011.

21. Baldi A, De Luca A, Morini M, Battista T, Felsani A, Baldi F, Catricalà C, Amantea A, Noonan DM, Albini A, Natali PG, Lombardi D and Paggi MG: The HtrA1 serine protease is downregulated during human melanoma progression and represses growth of metastatic melanoma cells. Oncogene 21: 6684-6688, 2002.

22. Tokunaga T, Nakamura M, Oshika Y, Abe Y, Ozeki Y, Fukushima Y, Hatanaka H, Sadahiro S, Kijima H, Tsuchida T, Yamazaki H, Tamaoki N and Ueyama Y: Thrombospondin 2 expression is correlated with inhibition of angiogenesis and metastasis of colon cancer. Br J Cancer 79: 354-359, 1999.

23. Tanabe Y, Hano H, Ichinokawa Y and Mathui T: Expression of dermokine in tumor lesion derived from oral stratified squamous epithelium. Tokyo Jikeikai Med J 128: 73-82, 2013 (In Japanese). 